NBER WORKING PAPER SERIES

\title{
TECHNOLOGY AND THE LIFE CYCLE OF CITIES
}

Elise S. Brezis

Paul Krugman

Working Paper No. 4561

NATIONAL BUREAU OF ECONOMIC RESEARCH

1050 Massachusetts Avenue

Cambridge, MA 02138

December, 1993

This paper is part of NBER's research program in International Trade and Investment. Any opinions expressed are those of the authors and not those of the National Bureau of Economic Research. 
NBER Working Paper \#4561

December 1993

\title{
TECHNOLOGY AND THE LIFE \\ CYCLE OF CITIES
}

\begin{abstract}
During times of major technological change leading cities are often overtaken by upstart metropolitan areas. Such upheavals may be explained if the advantage of established urban centers rests on localized learning-by-doing. When a new technology for which this accumulated experience is irrelevant is introduced, older centers prefer to stay with a technology in which they are more efficient. New centers, however, turn to the new technology, and are competitive despite the raw state of that technology because of their lower land rents and wages. Over time, as the new technology matures, the established cities are overtaken.
\end{abstract}

Elise S. Brezis

Department of Economics

Bar-Ilan University

Ramat-Gan

ISRAEL
Paul Krugman

Department of Economics

Massachusetts Institute of Technology

Cambridge, MA 02139

and NBER 
In his magisterial survey of urban history, Bairoch (1988) has noted that periods of revolutionary technological change are often marked by "upheaval in the urban hierarchy": old cities that remain locked into traditional industries are shouldered aside by upstart cities that embody the new. In time, of course, these upstarts are themselves often shouldered aside by yet newer urban centers. In some cases cities appear to go through a life cycle of growth and decay -- one need only mention the examples of Manchester or Detroit, each of which emerged from obscure beginnings to become a huge industrial center, then became a byword for metropolitan decline.

The rise of cities is evidently driven by circular causation, in which success reinforces success via some kind of external economy. Such external economies in some form underlie all models of urban systems, such as the classic work of Henderson (1974) and some of our own more recent work (Krugman 1991). But why do cities decline? Episodes of decline could represent no more than entropy: sooner or later, something is bound to come along that disrupts the virtuous circle of urban success. Yet it is hard not to suspect that there is some more fundamental process at work, one in which industrial development at some point occurs preferentially in new centers rather than old, established ones. That is, it seems plausible that there is a natural life cycle of urban rise and decline.

This paper offers one story about such a natural life cycle, a story that is rooted in a simple model of technological change that we have already applied to the question of cycles in national 
technological leadership (Brezis, Krugman, and Tsiddon 1993). The story is based on the assumption that the key external economies that support urban development are learning effects associated with the geographical concentration of industry. As long as the technology of an industry undergoes "normal" progress that builds on previous ideas, the interchange of knowledge among entrepreneurs and workers concentrated at an established industrial center will tend to preserve that center's leadership.

From time to time, however, new technological ideas arrive that are discontinuous with those that came before. Such major technogical changes may involve fundamental process innovation, like the replacement of open-hearth furnaces by the basic-oxygen process or the replacement of woven carpets with tufted pile. Or they may involve the introduction of new goods, like the displacement of carriages by automobiles. In either case, such technical changes offer the possibility of industry relocation, because for the new technologies the accumulated experience of existing industry concentrations may be of little value.

Meanwhile, existing industry concentrations present difficulties for new firms. Precisely because of their previous success, they are likely to be characterized by high land rents, prices, and wages. During periods of normal technological change these disadvantages are outweighed by the advantages of knowledge spillovers, but when a major technological shift occurs this "centripetal" force is weakened. The result then is that new technologies tend to be exploited in new centers. As the new 
technologies become increasingly productive, these new centers eventually outstrip the old.

This is an intuitive, perhaps even obvious story. In this informal version, however, it leaves several loose ends hanging. In particular, it is somewhat unclear how to think about the disadvantages of existing cities, and the reasons why such established centers do not themselves shift immediately to new technologies. These questions are closely related. If old centers do not immediately adopt new technologies, it must be because from their point of view the new is inferior to the old; if new centers are nonetheless able to enter the marketplace with these new technologies, it must be because any initial inferiority of the new techniques is offset by the advantages of not being required to produce in an established center. In other words, to make the argument clearly we must pay careful attention both to the specifics of technological change and to the negative effects of urban concentration; for both issues it is essential to develop a formal model.

The remainder of the paper lays out such a formal model. It begins by describing the assumptions of the model, then determines short-run equilibrium for an individual urban center of given population. The third part establishes the conditions under which a new technology will be exploited by a new urban center, leading to the decline of the established center. The final section offers some conclusions and suggestions for further research. 


\section{Assumptions of the model}

We consider an economy with a given labor force $L$, which produces and consumes two types of goods: food, a technically stagnant good with a constant-returns technology, and manufactures, a set of technically progressive goods subject to localized learning effects. We will refer to individuals employed in the production of manufactures as workers, and assign them numbers 0 to m-1. Those employed in the production of food will be referred to as farmers, and assigned the numbers from $m$ to $L$. (We will ignore the integer constraints and treat the distribution of labor as a continuous variable).

This will be a spatial economy, organized into one or more "city-regions." A city-region consists of a central business district or downtown, surrounded by a residential zone, itself surrounded by a food-supplying agricultural hinterland. It is assumed that manufactures production within such a city-region must take place within the central business district in order to take advantage of the knowledge accumulation from past production. However, workers require land to live on and thus must commute to the central business district. For simplicity we assume that workers do all their consumption at lunchtime, so that all of their expenditure takes place in the central business district.

Farmers are assumed to 1 ive on their farms, transporting food to the central business district for sale, and buying there the manufactured goods they desire. 
Workers are subject to commuting costs, and food is subject to transportation costs, in each case an increasing function of the distance to the central business district. Other things equal, these costs would make central locations more desirable. Given competition among workers and farmers, what must emerge is a land rent gradient that just offsets the advantage of better access. This then raises the question of who gets the land rents. For simplicity, we assume that there is a separate class of landlords who occupy no space and spend all of their income on manufactured goods.

We also make several other simplifying assumptions. Each worker requires one unit of land to live on, with no possibility of substitution; farmers also work with fixed coefficients. And we simplify the geography by making the city-region one-dimensional, with residential and agricultural land arrayed along a line of unit width (see Figure 1).

The agricultural sector

We begin with the agricultural sector. Farmers are distributed across the hinterland; we label them so that individual $m$ is closest to the center, individual $L$ furthest. Each farmer has one unit of labor, which she uses to produce food with a fixedcoeficient production function:

$$
Y_{\ell}=\min \left(L_{f} / \alpha, T\right) \quad \alpha<1
$$


Given this production function, each farmer will rent $1 / \alpha$ units of land and produce $1 / \alpha$ units of food. Since workers require only one unit of residential land, the assumption $\alpha<1$ effectively makes agriculture land-intensive relative to manufactures.

we assume that the utility function of each farmer takes a Cobb-Douglas form:

$$
U\left(Q_{m j}, Q_{f j}\right)=Q_{m j}^{\beta} Q_{f j}^{1-\beta}
$$

where $Q_{m j}$ and $Q_{f j}$ are the consumption of manufactures and food respectively by individual $j$.

Each farmer consumes part of her own production; the rest she sells at the central business district, using the proceeds to buy manufactures. To calculate the budget constraint of a typical farmer, we must take into account the costs of getting food to market. Transportation costs will be assumed to take samuelson's "iceberg" form, in which part of any food carried to the center is lost en route. Let $D_{j}$ be the fraction of a unit of food sent to market by farmer $j$ that actually reaches the central business district; $D_{j}$ will be a decreasing function of the farmer's distance from the center. The budget constraint of farmer $j$ will take the form

$$
p_{m} Q_{m j}=p_{f} D_{j}\left(1 / \alpha-Q_{t j}\right)-(1 / \alpha) R_{j}
$$

where $p_{m}$ is the price of manufactures and $p_{f}$ the price of food, both measured at the city center, and $R_{j}$ is the land rent paid by that 
farmer. Equation (3) can also be written as a conventional budget constraint,

$$
p_{m} Q_{m j}+p_{t} D_{j} Q_{f j}=p_{t} D_{j}(1 / \alpha)-(1 / \alpha) R_{j} \equiv E_{j}
$$

where $E_{j}$ is the income of individual $j$, including the imputed value of the food she grows for herself.

Rents are determined by the requirement that all farmers have equal welfare. Let $E_{l}$ be the income of the most distant farmer; then we must have

$$
E_{L} /\left(p_{m}^{\beta} p_{t}^{1-\beta} D_{L}^{1-\beta}\right)=E_{j} /\left(p_{m}^{\beta} p_{t}^{1-\beta} D_{j}^{1-\beta}\right)
$$

The most distant farmer, however, pays no rent; her income is simply $p_{f} D_{L} / \alpha$. Substituting back into equations (4) and (5) we therefore get the rent equation

$$
R_{j}=p_{t} D_{j}\left[I-\left(D_{L} / D_{j}\right)^{\beta}\right]
$$

Finally, we determine the food consumption of a typical farmer. Each farmer spends a fraction $1-\beta$ of her income on food:

$$
p_{f} D_{j} Q_{f j}=(1-\beta) E_{j}
$$

implying the demand equation for farmer $j$

$$
Q_{f j}=[(1-\beta) / \alpha]\left(D_{L} / D_{j}\right)^{\beta}
$$


The manufactures sector

We assume that the accumulated knowledge that makes the city an efficient place to produce manufactures is available only at the central business district, and that all manufactures production therefore takes place there. Workers must, however, have their unit of land to live on, and they therefore occupy a residential zone from which they must commute to the central business district.

Each worker is assumed to start with one unit of time. Commuting costs, however, use up part of this time. Let $T_{i}$ be the time that worker $i$ spends in commuting, with $T_{i}$ an increasing function of distance from the center. Then each worker provides only $1-T_{i}$ units of labor to the center. At any given time we let a be the productivity of manufacturing labor; then the output of worker $i$ is

$$
Y_{m i}=a\left(1-T_{i}\right)
$$

Workers consume manufactures and food, and share the same utility function as farmers. To avoid having different price indices for different workers, we assume that they do all of their consumption at the central business district, so that the budget constraint of a worker is

$$
p_{m} Q_{m i}+p_{f} Q_{f i}=p_{m} a\left(1-T_{i}\right)-R_{i} \equiv E_{i}
$$

where $R_{i}$ is the rent on his residential land. 
Residential land rent must be such that the real incomes of all workers are equalized. Since all workers face the same price index, this requires that

$$
E_{i}=E_{0}
$$

for all $i$.

It must therefore be true that

$$
R_{0}-R_{i}=p_{m} a T_{i}
$$

Also, the rent of the last worker and the first farmer must be the same, so we must have

$$
R_{0}-p_{m} a T_{m}=p_{L} D_{m}\left[1-\left(D_{L} / D_{m}\right)^{B}\right]
$$

The rent at the center of the city-region is therefore

$$
R_{0}=p_{m} a T_{m}+p_{f} D_{m}\left[1-\left(D_{L} / D_{m}\right)^{\beta}\right]
$$

All workers will have the same consumption pattern, with the consumption of food per worker equalling

$$
p_{t} Q_{t i}=(1-\beta) E_{i}
$$

\section{Short-run equilibrium}

Given the labor force $L$ and the productivity of manufacturing 
workers a, it is straightforward to determine the equilibrium allocation of land and labor, together with the implied land rents.

It will be convenient at this point to adopt manufactured goods as our numeraire, since these goods are assumed to be costlessly transported and hence have the same price everywhere.

Equilibrium requires that two conditions be satisfied. First, the real income of farmers and workers must be equalized, implying:

$$
E_{0} /\left(p_{m}^{\beta} p_{f}^{1-\beta}\right)=E_{L} /\left(p_{m}^{\beta} p_{t}^{1-\beta} D_{L}^{1-\beta}\right)
$$

From this we can derive a relationship that links the commuting cost of the last worker, the transport cost of the last farmer, and the relative price of food:

$$
\frac{p_{m}}{p_{l}} a\left(1-T_{m}\right)-V=D_{L}^{\beta} / \alpha \text { where } V=D_{m}\left[1-\left(D_{L} / D_{m}\right)^{\beta}\right]
$$

We may immediately note that for given $L$, an increase in $m$ will increase both $T_{m}$ and $D_{L}$. For (17) to continue to hold this must be offset by a fall in $p_{f}$. Intuitively, if there are more workers and fewer farmers, this will tend to reduce the real income of workers compared with farmers unless offset by a fall in the relative price of food. Thus (17) defines the downward-sloping schedule UU in Figure 2 .

The second equilibrium condition is market-clearing for food. The net supply of food from farmers is their total output less their own consumption: 


$$
N S=\int_{m}^{L} D_{j}\left(1 / \alpha-Q_{f j}\right) d j
$$

Given the demand of workers (16), the food demand of workers is

$$
\int_{0}^{m} Q_{f i} d i=\left[(1-\beta) m E_{0}\right] / p_{t}=\left[(1-\beta) m\left[p_{m} a\left(1-T_{m}\right)-p_{t} V\right]\right] / p_{t}
$$

The market equilibrium condition is therefore

$$
\left[(1-\beta) m\left[p_{m} \frac{a}{p_{l}}\left(1-T_{m}\right)-V\right]\right]+\left[(1-\beta) D_{L}^{\beta} / \alpha\right] \int_{m}^{L} D_{j}^{1-\beta} d j=[1 / \alpha] \int_{m}^{L} D_{j} d j^{(20)}
$$

Inspection of (20) reveals that an increase in m increases the demand for food and reduces the supply; this must be offset by a rise in $p_{f}$. Thus (20) defines an upward-sloping schedule, shown as $F F$ in Figure 2. The intersection of $F F$ and $U U$ determines the equilibrium allocation of labor and relative price of food.

It will be useful to know how this equilibrium is affected by changes in two parameters: the productivity of manufacturing labor a and the size of the labor force $L$.

We first note that in both (17) and (20) the parameter a always enters in the form $a / p_{f}$. Thus an increase in a is matched by an equal rise in the relative price of food (fall in the relative price of manufactures), with no change in the spatial structure of the city-region. (This is an artifact of cobb-Douglas preferences). It follows that the welfare of all individuals rises in the same 
proportion: a one percent rise in a produces a $\beta$ percent rise in utility for workers and farmers alike.

Next, we note that an increase in $L$ for a given a can be expected to reduce the real income of the typical individual. This seems intuitively obvious: an increase in the labor force pushes out both the commuting and the agricultural margins. Because the relative price of food may change, however, it is difficult to prove; we offer an illustrative numerical example in the appendix. The implication of these two results is that the utility of the representative individual in a city-region, whether worker or farmer, may be described by a function that is increasing in the productivity of manufacturing workers and decreasing in the cityregion's population:

$$
U=U(a, L)
$$

\section{Dynamics of technical change}

We now introduce the dynamics of technical change. Technology is assumed to progress in two ways. First, within a technological generation there is steady learning based on local experience. second, there are occasional major technical changes in which new methods are introduced for which previous experience is irrelevant. within a technological generation, productivity is an increasing function of cumulative experience within a city: 
where $\mathrm{K}$ is the cumulated manufacturing output produced in the city:

$$
K(t)=\int_{0}^{\tau} \int_{0}^{m} Y_{m i}(\tau) d i d \tau
$$

We assume that $a^{\prime}>0, a^{\prime \prime}<0$; that is, learning effects are positive, but there are diminishing returns to experience.

Notice that the increasing productivity of a city-region over time raises its real income but does not affect the allocation of its labor between workers and farmers.

Next we consider the introduction of new technologies.

suppose that a new technology is introduced. It may represent a new way of producing the same manufactures, or a new kind of manufactures. If the latter is the case, we assume for simplicity that the new good is a perfect substitute for the old, so that we can think of simply introducing a new learning schedule $a^{*}\left(K^{*}\right)$, where $K^{*}$ is cumulative experience using the new technology. That is, past experience is irrelevant.

We will make three assumptions about the relationship of the new technology to the old. First, the new technology is potentially superior, in the sense that $a^{*}(x)>a(x)$ for any $x$ : for any given amount of relevant experience workers using the new technology will be more productive.

Second, we assume that despite this potential advantage, for the established center the new technology is initially inferior to 
the old:

$$
a \cdot(0)<a(K)
$$

Finally, we assume that while initially inferior to the old technology, the new technology is good enough that in a city-region with small population and thus low rents and costs of transportation and commuting, it allows a higher utility than that in the established center:

$$
U(a \cdot(0), 0)>U(a(K), L)
$$

Given these assumptions, we can immediately see what happens. When the new technology becomes available, producers in the established center do not adopt it, because given their experience they remain more productive with the old technology. A new, smaller center comes into being, however, because the new technology is good enough to compete with the old given the extra advantage of low commuting and transport costs. The relative sizes of the two city-regions will be determined by the necessity. of equal utilities. Let $L^{1}$ be the labor force of the old center, $L^{2}$ that of the new center. Then equilibrium may be represented by Figure 3 , in which $U^{1}$ and $U^{2}$ represent the utility of typical workers in each location as a function of the city-region's labor force: population will move to equalize welfare of individuals in the two centers. Where will the new center be located? In general, given our assumptions, this is indeterminate; all that we can say is that the 
new central business district will be at least as far away from the existing one as the last farmer just before the innovation, because the incentive is always to choose a location with zero land rents and a minimal price of food. We might invoke very small advantages of being close to the existing center to propose that the new center will be located precisely at that agricultural margin; but in any case this plays no role in the story.

over time, as the productivity of workers rises through learning in both locations, both schedules in Figure 3 will shift up. Given the diminishing returns to experience, however, a should rise more rapidly than a. Recall that welfare for a given $L$ is homogeneous of degree $\beta$ in a; a rise in $a^{*} / a$ implies that $U^{2}$ will rise more than $U^{1}$, as illustrated in Figure 3, so that over time the existing center will decline and the new center gain population at its expense.

This is precisely the story we sketched out in the introduction. From the point of view of the experienced producers in the existing center, the new technology is inferior to the old. Thus the existing center does not adopt the new technique. Nonetheless, it is profitable to introduce the new technology in a new location that does not suffer the diseconomies associated with the large population of an established city-region. And as the new technology matures through learning, both the new technology and the new city-region that are based upon it take over from the established region. 
This paper offers a simple model that may explain the existence of a natural life-cycle for urban centers, suggesting that the very success of an urban center in a traditional technology may make put it at a disadvantage in the implementation of a newer, ultimately more productive new technology. The model thus provides a rationale for grand cycles of urban rise and decline, suggesting that they are not simply matters of historical accident but may reflect a deeper underlying logic.

APPENDIX: EFFECTS OF AN INCREASE IN THE LABOR FORCE

It seems intuitively obvious that an increase in the labor force in a city-region should reduce the welfare of residents for a given level of productivity a. (over time, of course, a larger manufacturing sector will mean faster technological progress). It is, however, quite difficult to prove. There are proofs of a seemingly similar proposition in the urban economics literature; see, for example, fujita (1988). The fact that relative prices change in our model, however, makes the analogy with standard urban models imperfect.

Rather than offer a general proof, we provide here a suggestive numerical example. We assume that commuting costs and transportation costs take the following forms:

$$
1-T_{m}=e^{-\tau m}
$$

and 
with $T>\delta$.

We have computed equilibrium for the following parameters: T $=.4, \delta=.05, \beta=.5, \alpha=.1, a=1$. Table 1 shows how $m, p_{4}$, and $U$ are affected by the labor force. In this example, we see that welfare is indeed reduced by an expansion of city-region size.

Table 1

$\begin{array}{cccc}\text { L } & 1 & 2 & 3 \\ \text { m } & 0.511 & 1.048 & 1.604 \\ \text { pf } & 0.092 & 0.083 & 0.075 \\ \text { U } & 2.65 & 2.22 & 1.85\end{array}$

\section{REFERENCES}

Bairoch, P. (1988), Cities and Economic Development: From the Dawn of History to the Present Chicago: Chicago University Press.

Brezis, E., Krugman, P., and Tsiddon, D. (1993), "Leapfrogging: a theory of cycles in national technological leadership", American Economic Review, september.

Fujita, M. (1988), Urban Economic Theory, Cambridge: Cambridge University Press. 
Henderson, J.V. (1974), "The sizes and types of cities", American Economic Review 64, 640-56.

Krugman, P. (1991), Geography and Trade, Cambridge: MIT Press. 
City center

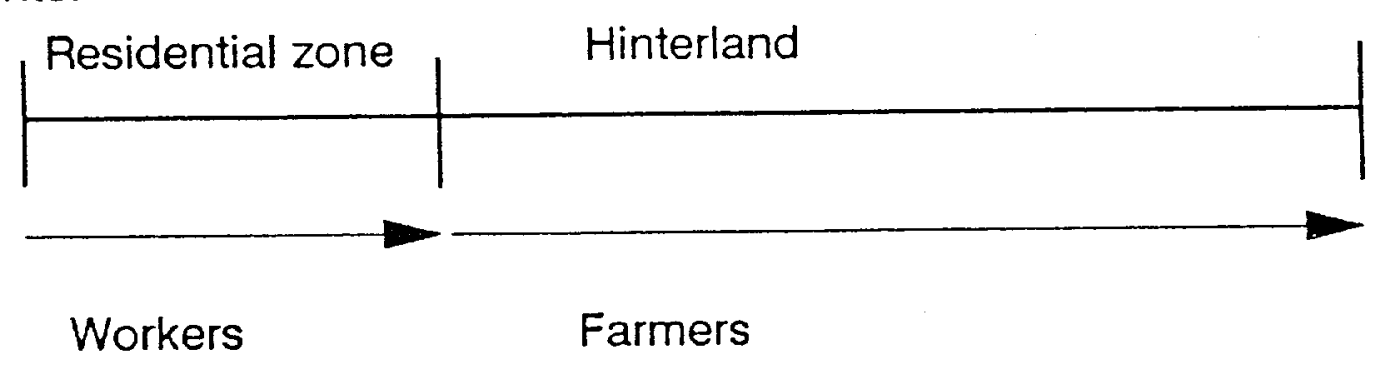

FIGURE 1 


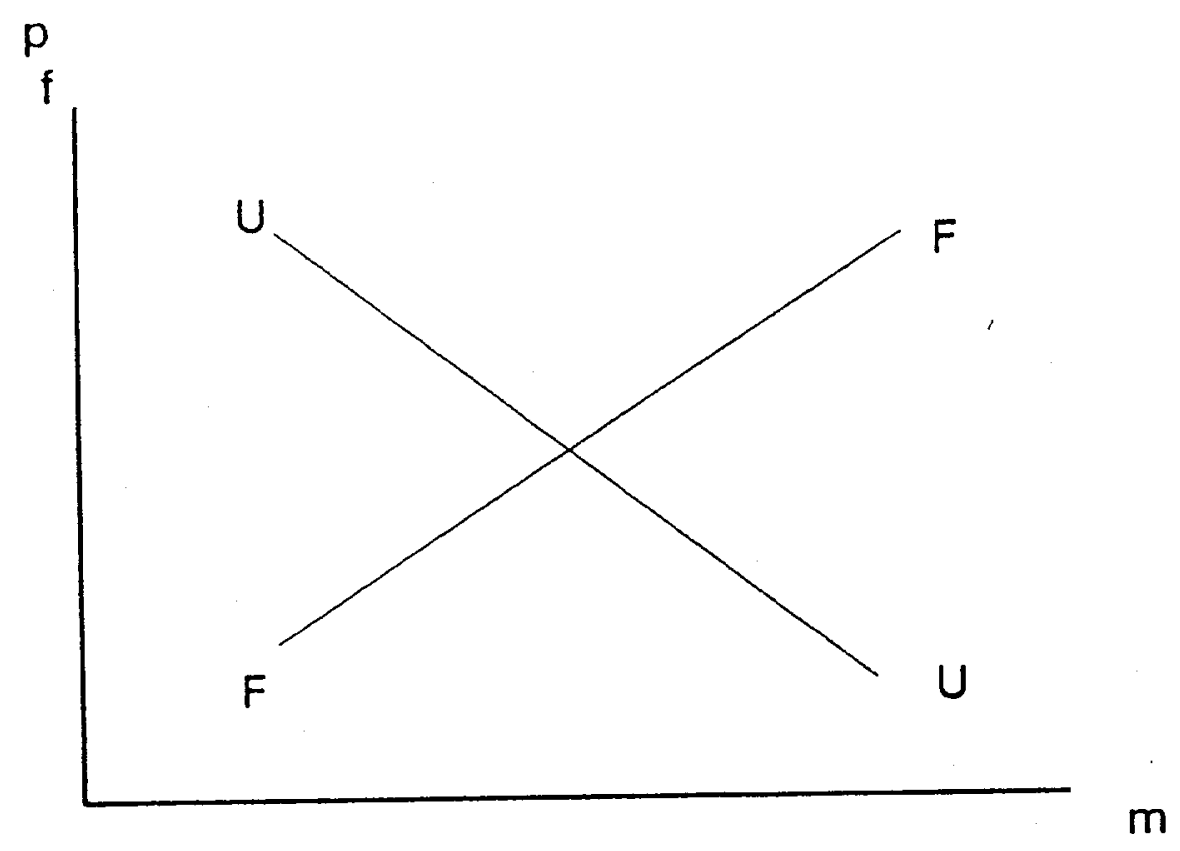

FIGURE 2 


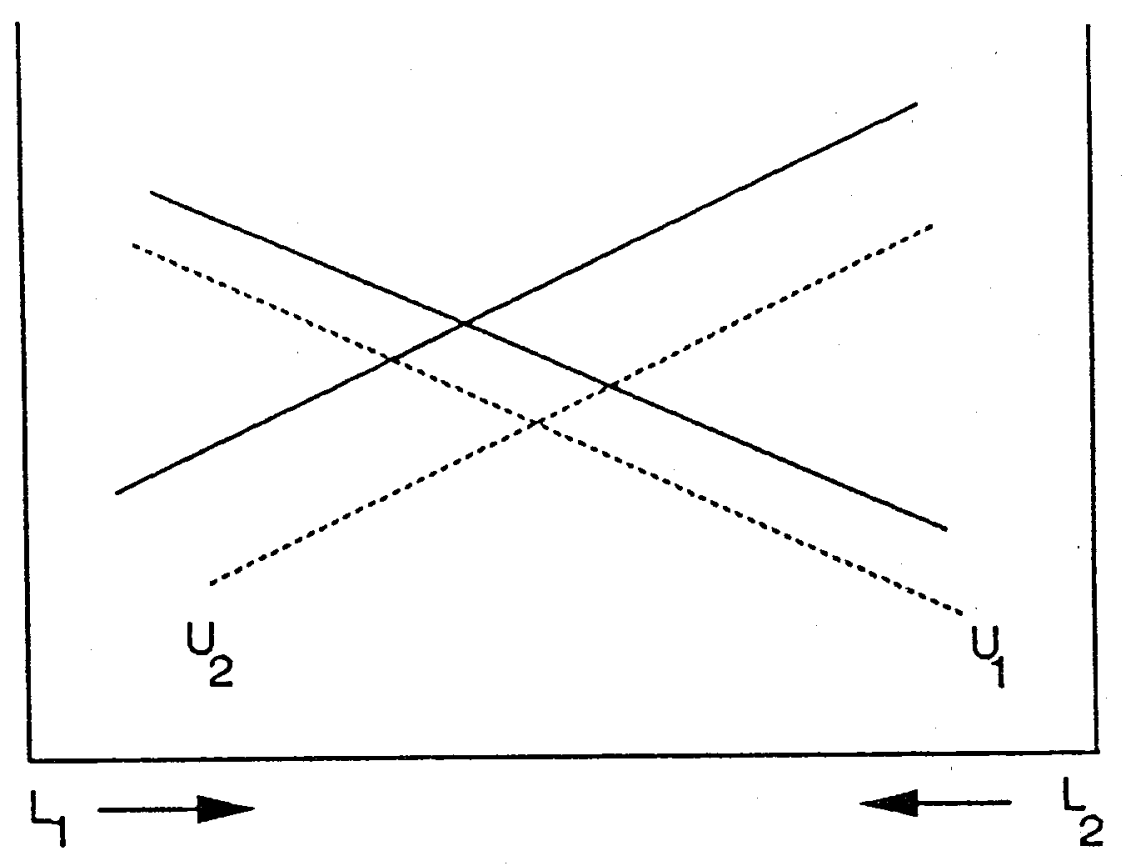

FIGURE 3 